\title{
A OCUPAÇÃo dAS VÁRZEAS NO ALTO TIETÊ E A REPRODUÇÃo DESTE MODELO URBANO NA BACIA DO RIO BAQUIRIVU GUAÇU, GUARULHOS E ARUJÁ - SP
}

\author{
Antonio Manoel dos Santos Oliveira* \\ Daniel Carlos de Campos**
}

Resumo: Embora as inundações sejam fenômenos naturais, condicionadas por diversos aspectos do meio físico, nas áreas urbanas, o homem, por meio de suas atividades econômicas, transforma estes eventos em problemas. Nesse contexto, as experiências acumuladas ao longo do século XX na Bacia do Alto Tietê constituem importante referencial para a análise do uso do solo na Bacia do Rio Baquirivu Guaçu, como experiência a ser considerada na seleção de medidas a serem tomadas para o controle das inundações.

Palavras-chave: inundação, Baquirivu Guaçu, Bacia Hidrográfica do Alto Tietê, expansão urbana.

\section{THE OCCUPATION WATERSHAD OF ALTO TIETÊ AND THE REPRODUCTION OF THIS URBAN MODEL IN RIVER BAQUIRIVU GUAÇU, GULHUROS AND ARUJÁ - SP}

\begin{abstract}
Although floods are natural phenomena, conditioned by various aspects of the physical environment, in urban areas, man, through their economic activities, transforms these events into troubles. In this context, the experience accumulated over the twentieth century in the Alto Tietê watershed is an important reference for the analysis of land use in the Baquirivu Guaçu watershed as an experience to be considered in the selective of measures to be taken for inundation control.
\end{abstract}

Key Words: inundation, Baquirivu Guaçu, watershad of Alto Tietê, expansion sprawl.

\section{Introdução}

Dentre as diversas conceituações

(e.g. Jorge e Uehara, 1998; Riccomini; Giannini e Mancini, 2000; Mattes, 2001; Tucci, 2006), no presente trabalho, considera-se inundações, cheias e enchentes como processos naturais de extravasamento das águas, quando de precipitações intensas, para as áreas marginais dos cursos d'água, ou seja, suas planícies de inundação, várzeas ou leito maior dos rios, sendo parte integrante do ciclo hidrológico. Alagamentos, por sua vez, são causados pela falta ou insuficiência do sistema de microdrenagem, incapaz de promover o escoamento das águas, e não se relacionam ao regime fluvial, ou seja, ocorrem em áreas que não constituem várzeas ou planícies de inundação. As inundações, em condições naturais, portanto, estão condicionadas, principalmente, pela intensidade, freqüência e duração das chuvas e sua distribuição na bacia hidrográfica, definindo os espaços de acomodação das águas que excedem o canal ou leito menor, a depender das declividades das vertentes e do talvegue principal e da geomorfologia fluvial - as planícies de inundação ou várzeas.

A cobertura vegetal participa de maneira ponderada nas inundações. Segundo Karmann (2000), áreas florestadas de clima 
quente e úmido devolvem à atmosfera cerca de $70 \%$ da precipitação. Este processo de retenções e liberações de água sob forma de vapor assegura os altos teores de umidade encontrados nas florestas que, assim, cumprem importante papel regulador da temperatura, do ar e das chuvas. Cerca de $30 \%$ é retardado pela cobertura vegetal e escoa pela superfície das vertentes de maneira lenta e gradual, ou se infiltram no solo, até chegar aos cursos d'água. A vegetação serve também como proteção ao impacto direto da chuva no solo, controlando os processos erosivos. Portanto, as inundações, em condições naturais, são condicionadas por diversos aspectos do meio físico, constituindo-se em processos altamente dinâmicos e evolutivos.

O homem promove profundas modificações, neste cenário natural, mediante atividades sociais, econômicas e políticas, com reflexo na urbanização, causando desequilíbrios no balanço hídrico de uma bacia.

Para Serra (1987), é por meio "dos aspectos tecnológicos da cultura que os homens modificam seu meio ambiente, $[\ldots]$, adaptando-se às suas necessidades". Assim, aspectos do meio físico, durante milhares de anos, foram limitadores da ocupação humana. A partir do avanço tecnológico, como as retificações dos cursos d'água e o aterramento das várzeas, foram criadas as condições para a urbanização.

Segundo Seabra (1987), nesse processo os setores públicos e privados caminham juntos na produção da cidade, e é pela via do Estado, teoricamente garantidor do interesse público, que se criam condições gerais para a concretização do fenômeno urbano. A autora afirma ainda que no desenvolvimento das relações de produção capitalista são criadas maneiras de apropriação da terra, pois, antes de tudo, ela é um meio de produção, além de ser uma mercadoria como outra qualquer.

Assim, o processo de urbanização inicia-se, normalmente, pela abertura de lotes ou loteamentos nas vertentes, em terrenos com relevo mais suave, como as colinas, e distantes das áreas inundáveis. Nesse cenário, o processo de ocupação urbana e de alterações dos processos geohidrológicos, de um modo geral, segue a seguinte sequência: 1 . supressão da cobertura vegetal - diminuição do processo de evapotranspiração e aumento do escoamento superficial; 2 . erosão e assoreamento - intensificação do escoamento nas vertentes e diminuição da capacidade hidráulica dos cursos d'água; 3 . impermeabilização do solo - segundo Tucci (2006) provoca o aumento de até sete vezes no escoamento superficial em relação às condições naturais; 4. canalizações e retificações - aumento da condutividade hidráulica dos cursos d'água, elevando as vazões à jusante; 5. ocupação das várzeas mediante seu aterramento, confinando as águas, e transferindo-as à jusante com mais intensidade; 6. implantação de condutos e travessias mal dimensionadas - criando pontos de inundações localizados; e 7 . obstrução da drenagem por resíduos sólidos - gerados pelos processos erosivos nas vertentes, pela construção civil e os produzidos industrialmente. Apesar da idéia muito disseminada de que o lixo é o principal condicionante das inundações, ele é incipiente nos espaços das calhas dos principais rios. Realizando estudos na calha do Rio Tietê, Santos (2002) afirma:

o lixo urbano, ainda que se destaque no aspecto visual, representa apenas $5 \%$ do volume total de material de assoreamento, ou seja, 95\% deste volume correspondem a sedimentos finos provenientes dos processos erosivos e material areno-pedregoso originado da construção civil (SANTOS, op. cit.). 


\section{Objetivo e justificativas}

O objetivo do presente trabalho é o de analisar as inundações e seus condicionantes na Bacia do Rio Baquirivu Guaçu, à luz das intervenções hidráulicas nos principais rios da Bacia do Alto Tietê - BAT, tendo em vista a necessidade da aplicação de medidas preventivas, destinadas ao controle das inundações. A Bacia Baquirivu Guaçu está a nordeste da BAT e da Região Metropolitana de São Paulo -RMSP, nos Municípios de Guarulhos e Arujá (Figura 01). Considerando o Tietê e Pinheiros como um único sistema, a Bacia do Rio Baquirivu Guaçu, com 165,5 km², é a segunda maior na área urbana da BAT, menor somente do que a do Tamanduateí, com $320 \mathrm{~km}^{2}$.

Figura 01. Bacia do Alto Tietê e da Bacia do Rio Baquirivu Guaçu. Fonte: Emplasa (2002).

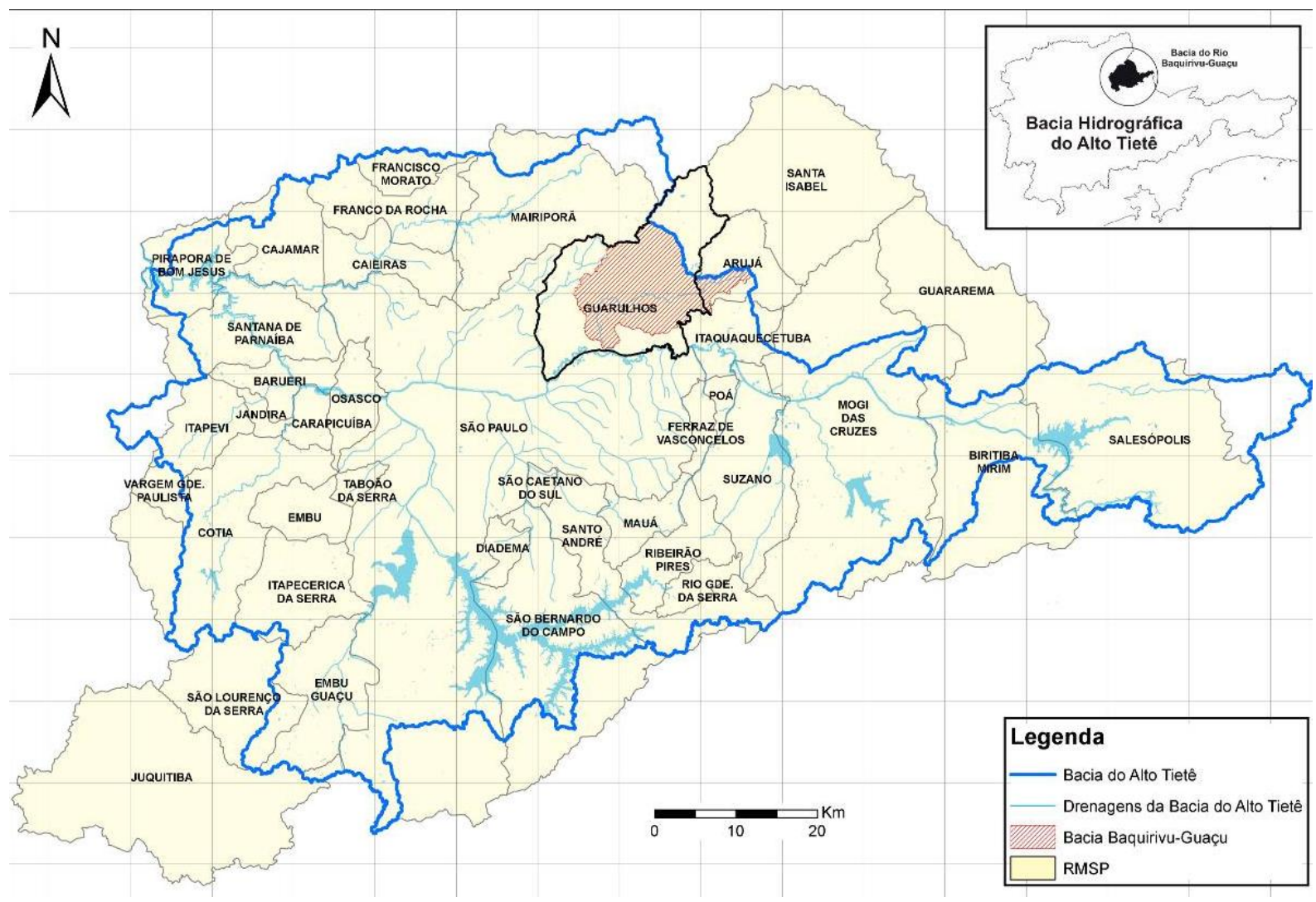

\section{Materiais e Método}

Para a elaboração do presente trabalho, foi realizada uma breve revisão histórica da ocupação urbana e das intervenções nos rios Tietê e Pinheiros, como referencial para a análise do potencial das inundações no Rio Baquirivu Guaçu. Para tanto, foi realizada a descrição do meio físico e as alterações decorrentes da urbanização da BAT, com vista a relacioná-los ao comportamento do escoamento superficial na bacia do Rio Baquirivu Guaçu, por meio de análise de mapeamentos pré-existentes. 


\section{Construção de um referencial: quadro regional}

A BAT corresponde à área drenada pelo Rio Tietê, desde sua nascente, no município de Salesópolis, até a Barragem de Rasgão, num total de $5.985 \mathrm{~km}^{2}$. Dos 39 municípios da RMSP, 36 estão total ou parcialmente inseridos na BAT. Caracteriza-se por apresentar regimes hidráulicos e hidrológicos extremamente complexos, em virtude das alterações produzidas pela urbanização durante o último século CBHAT (2002).

Localiza-se no Planalto Atlântico, em área de Mata Atlântica, com uma precipitação média anual de $1.500 \mathrm{~mm}$. As cabeceiras encontram-se em terrenos cristalinos de morros e serras dos maciços da Serra da Cantareira (ao norte, altitudes de até $1.200 \mathrm{~m}$ ), e da Serra do Mar ao sul (altitudes de até $1.000 \mathrm{~m}$ ). Estes maciços circundam as colinas da Bacia Sedimentar de São Paulo, onde se formaram suas planícies aluviais, pouco acima da altitude de $700 \mathrm{~m}$, se estendendo de forma significativa de leste para oeste, até Barueri, onde os morros cristalinos estrangulam as planícies, passando o Rio Tietê a correr em vale fechado. Há, portanto, significativa superposição da bacia hidrográfica quaternária com a sedimentar terciária, onde se destacavam, antes das obras de retificação, os meandros do Rio Tietê, sugerindo a persistência de vocação de área de deposição ou agradação nas planícies aluvionares, no tempo geológico, portanto, sujeitas às inundações periódicas. Ab'Saber (1957) distingue dois níveis altimétricos onde ocorrem as inundações: planícies sujeitas às grandes cheias, entre 722 e 724 m, e sujeitas às inundações anuais entre 719 e $721 \mathrm{~m}$.

\subsection{Expansão da urbanização na RMSP e na BAT}

O início do processo de urbanização significativa na BAT remonta à segunda metade do século XIX quando começaram a florescer as atividades associadas à economia cafeeira, promovendo grande expansão do mercado de trabalho, gerando migrações de trabalhadores. Em decorrência, segundo Sempla (2010), a Capital passou de 30 mil habitantes em 1872, para 65 mil em 1890, dando um grande salto, entre 1890 e 1900, para 240 mil. Em 1950 atingiu 2,2 milhões de habitantes, conforme Quadro 01.

Quadro 01. Taxas de crescimento populacional - 1872 a 2010

\begin{tabular}{|c|c|c|c|c|}
\hline \multirow{2}{*}{ Anos } & \multicolumn{2}{|c|}{ Município de São Paulo } & \multicolumn{2}{c|}{ Região Metropolitana de SP } \\
\cline { 2 - 5 } & População & Taxas de & População & Taxas de \\
\hline 1872 & 31.385 & & - & \\
\hline 1890 & 64.934 & 106,89 & - & \\
\hline 1900 & 239.820 & 279,33 & - & \\
\hline 1920 & 579.033 & 141,44 & & \\
\hline 1940 & 1.326 .261 & 129,05 & & 67,26 \\
\hline 1950 & 2.198 .096 & 65,74 & & 71,75 \\
\hline 1960 & 3.781 .446 & 172,03 & & 54,66 \\
\hline 1970 & 5.924 .615 & 56,68 & & 22,69 \\
\hline 1980 & 8.493 .226 & 43,35 & & 15,76 \\
\hline 1991 & 9.646 .185 & 13,57 & & 10,1 \\
\hline 2000 & 10.434 .252 & 8,17 & & \\
\hline 2010 & 11.253 .503 & 7,85 & & \\
\hline
\end{tabular}

Fonte: IBGE

A partir da década de 1940, especialmente em São Paulo, houve uma crise estrutural, decorrente da II Guerra Mundial no mercado de provisão habitacional, segundo Bonduki (1998). Ao mesmo tempo verificou-se um enorme êxodo das áreas rurais do Estado de São Paulo para a RMSP, principalmente para a Capital, de uma população que procurava melhores oportunidades 
que vieram a surgir com a expansão do parque industrial e das atividades comerciais. Nesse período, a especulação oriunda do processo de industrialização reuniu as classes, média e alta, e expulsou as camadas mais pobres da sociedade dos centros urbanos consolidados (BONDUKI, op. cit.). Começou então um movimento em que centenas de trabalhadores ocuparam loteamentos na periferia da Capital e cidades vizinhas, provocando a expansão urbana. Neste processo, várias famílias fixaram-se de modo irregular, em áreas onde a terra ainda não era de interesse do mercado imobiliário, ou seja, nos fundos dos vales e nas vertentes de altas declividades, gerando áreas de riscos às inundações e aos escorregamentos.

A partir de 1970, apesar da redução do crescimento populacional e a diminuição dos fluxos migratórios de outras localidades para a RMSP, estabeleceu-se um esvaziamento populacional nas regiões centrais mais servidas de infraestrutura e, simultaneamente, um aumento populacional acompanhado de um crescimento horizontal da urbanização nas áreas periféricas mais carentes de infraestrutura, conforme Figura 02.

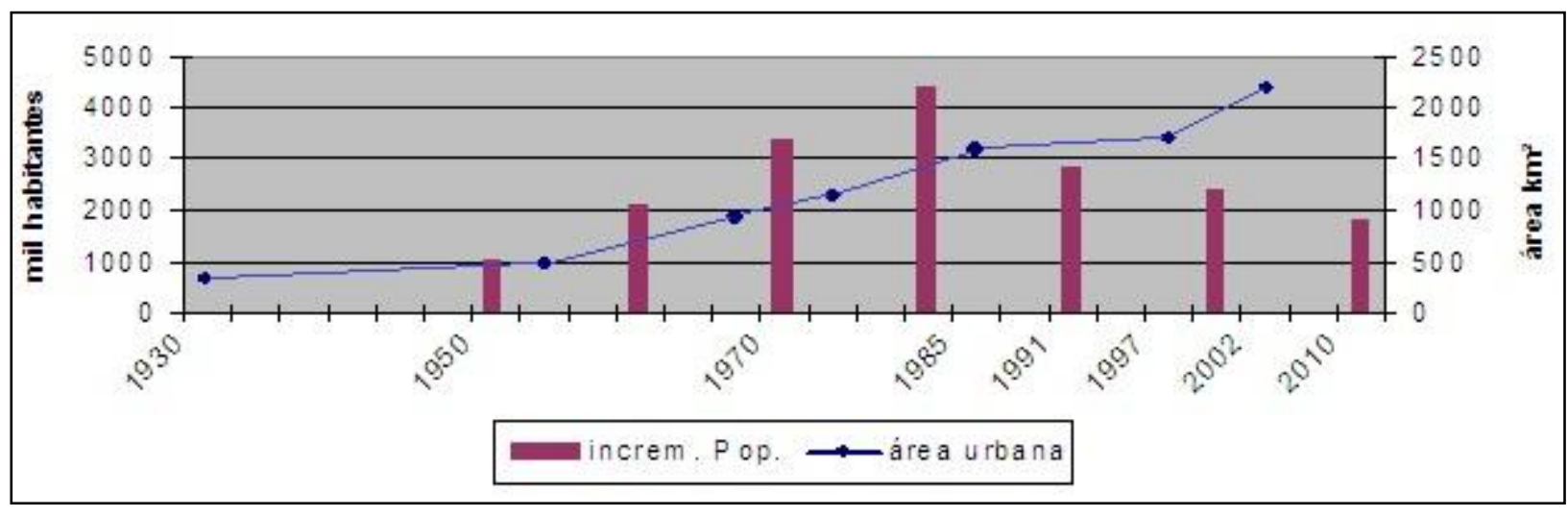

Figura 02. Gráfico da expansão da área urbana em km², segundo CBHAT (2000) e Emplasa (2002) incremento populacional da RMSP, segundo Nadalin e Igliori (2010), compilado por (CAMPOS, 2011).

E ainda, segundo Stevaux (2010), a área urbana da BAT passou de $190 \mathrm{~km}^{2}$ em 1930, para 1900 km² em 2001, ou seja, crescimento de 10 vezes em 70 anos.

O avanço da expansão urbana, a partir da segunda metade de 1970, foi concomitante ao processo de desindustrialização na RMSP, estabelecendo uma tendência oposta à relação clássica de crescimento industrial e de urbanização. Para Davis (2006), a expansão urbana sem crescimento econômico é resultado de uma conjuntura global, relativa à crise mundial da dívida externa do final dos anos de 1970 e a conseqüente reestruturação das economias do Terceiro Mundo que levou a migração de populações carentes às periferias urbanas. Ao mesmo tempo, a omissão dos poderes públicos e, consequentemente, a intensificação da especulação imobiliária na RMSP, gerou exclusão sócioespacial como pode ser observado na Figura 03. 


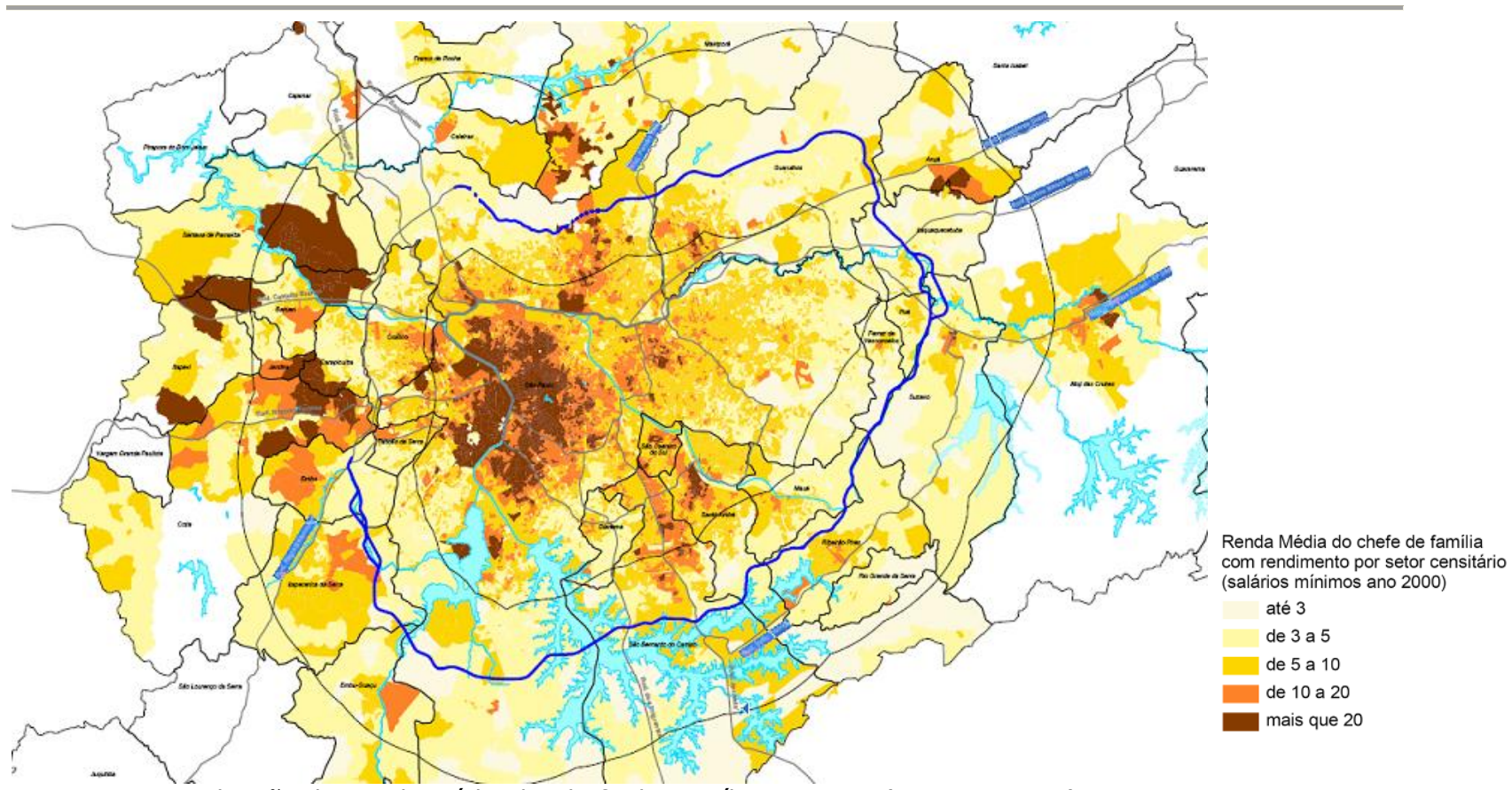

Figura 03. Distribuição da Renda Média do Chefe de Família na RMSP (FESPSP, 2004).

\subsection{Medidas corretivas na BAT}

As intervenções nos principais cursos d'água na BAT foram assentadas em duas concepções básicas: (1) canalizações e retificações, entre o final do século XIX até 1980, com duas abordagens (sanitarista e de controle das inundações) e (2) reservação dos volumes à montante, oposto ao primeiro, mediante a implantação de reservatórios de detenção, a partir de 1990, destinadas ao controle das inundações.

\subsubsection{Canalizações e retificações}

Entre o fim do século XIX e início do XX, as obras hidráulicas eram fortemente induzidas mais pelas necessidades sanitárias, devido aos surtos de epidemias que estavam atingindo a população, do que pelos prejuízos que as inundações causavam, segundo Mattes (2001). Entretanto, ao serem implantadas, as obras reforçavam interesses implícitos de setores econômicos, como o aproveitamento hidroenergético e a viabilização da ocupação das várzeas para fins imobiliários.

Conforme Serra (1987) apontou, a reprodução urbana decorre das relações de poder existentes no modo de produção social no espaço e no tempo. Devido à dificuldade de controlar o custo e uso da terra pelo conjunto da sociedade, os interesses vocacionais e econômicos particulares se sobrepõem, segregando e classificando o espaço urbano. Neste contexto, a retificação dos rios Tietê e Pinheiros e o aterramento de suas várzeas, na primeira metade do século XX, possibilitaram a expansão urbana de São Paulo, como demonstraram Seabra (1987) e Mattes (2001), viabilizando grandes negócios imobiliários. Seabra (op. cit.) demonstrou como a Brasilian Traction Light \& Power Cy. Ltd., ou simplesmente Light elaborou por aproximadamente trinta anos, estratégias diferenciadas com o objetivo de garantir seus interesses na exploração hidroenergética e na valorização das várzeas do Rio Pinheiros, mediante o controle das barragens do Parnaíba, ocasionando a "grande enchente de 1929", possibilitando a incorporação de vastas terras ao seu patrimônio. 
Em 1943, o Rio Pinheiros havia sido totalmente retificado e, em 1957, seu canal foi transferido à administração pública, a Light fazia apenas sua manutenção e era proprietária de praticamente toda a várzea. Por fim, a reversão do curso do rio Pinheiros, para geração de energia elétrica, possibilitou também o controle das inundações, tornando suas várzeas uma das regiões mais valorizadas de São Paulo, fatos que constituem a essência do modelo de reprodução urbana na BAT, ou seja, as medidas tomadas para a valorização do preço do $\mathrm{m}^{2}$ urbano.

Em relação ao Rio Tietê, sua retificação foi marcada, na década de 1920, pelo embate técnico entre dois notórios engenheiros. De um lado Saturnino de Brito e de outro o engenheiro Prestes Maia. Saturnino de Brito preconizava o resgate da orla fluvial urbana, preservando o leito maior dos rios. Em seu texto de justificativa do projeto, destaca a importância das matas na regularização das vazões do Tietê e a necessidade de manter à montante de São Paulo, o atual regime de inundações de suas várzeas (BRITO, 1926). Lembrava também que a inundação é um fenômeno natural e que as várzeas constituem elementos reguladores das águas correntes. Por outro lado, o engenheiro Francisco Prestes Maia, juntamente com o colega João Florence de Ulhoa Cintra, a pedido do então Prefeito da Capital, José Pires do Rio (1926 - 1930), elaboram um plano viário (Plano de Avenidas), que previa um sistema radial concêntrico, com a ocupação dos fundos de vale, áreas ainda desocupadas e que, com baixos custos, serviam ainda para a valorização dos terrenos no entorno após a obra. Entretanto, Pires do Rio finalizou seu mandato sem viabilizar o plano.

Figura 04. Mapa do canal original do Tietê e retificação realizada até 1943 (LIGHT, 1943).

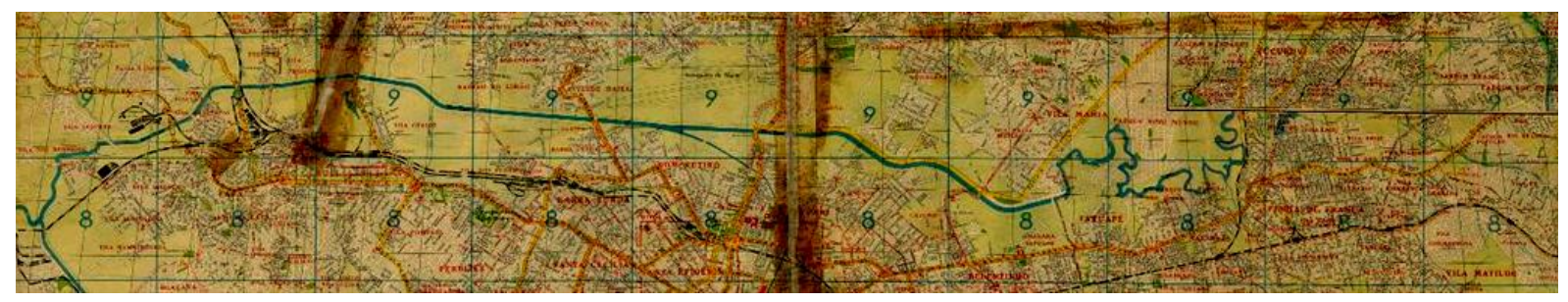

Em 1937, a coordenação das obras de retificação do Rio Tietê é assumida por Ulhoa Cintra e o projeto da Comissão de Melhoramentos, apresentado por Saturnino de Brito, fora abandonado em muitos de seus aspectos (MATTES, 2001).

O interventor Adhemar de Barros indica, em 1938, o engenheiro Prestes Maia como prefeito da Capital, cargo que exerceu até 1945. Nesse período, o engenheiro realizou parte da retificação do Rio Tietê, além de uma série de outras obras de canalização e abertura de vias.

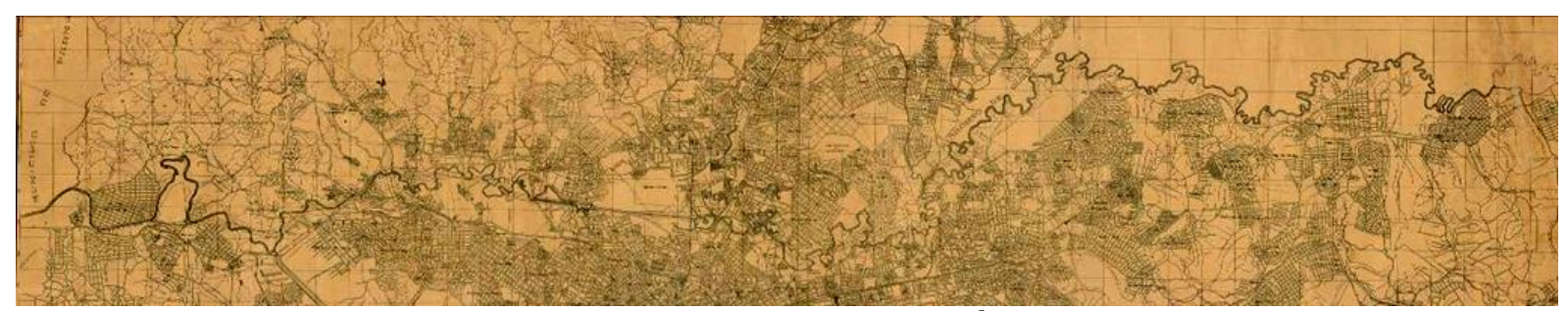

Figura 05. Mapa da retificação realizada até 1952 (LORENZ, 1952).

Entre as décadas de 1940 e 1950, a cidade de São Paulo apresentava índices de crescimento populacional acima de 5\% a.a, aumentando a necessidade de mais pessoas habitarem e se locomoverem, acelerando assim as obras de infraestrutura, em especial, a retificação do Rio Tietê, conforme Figuras 04 e 05. 
Segundo Ab'Saber (1957), em 1950, as obras no Pinheiros e no Tietê, "aliadas à ação do sistema hidráulico criado pela Light, destruíram o regime hidrológico antigo."

Em 1968, o Governo do Estado desenvolveu estudos (HIBRACE) abrangendo a BAT como um todo, pois houve um entendimento que as inundações no Rio Tietê, especialmente na década de 1970, não estavam mais circunscritos à Capital. Tal estudo recomendava o controle das vazões, mediante a construção de reservatórios nas cabeceiras, ou seja, Ponte Nova, Taiassupeba, Paraitinga I e II, Biritiba e Jundiaí, obras, inclusive, recomendadas por Saturnino de Brito em 1926.

Entre 1969 e 1973, no período conhecido por "milagre econômico", no governo de exceção do Presidente Emílio Garrastazu Médici, intensificou-se a implantação do sistema viário em fundos de vales e as canalizações.

Em 1982, à montante da Barragem da Penha, $15 \mathrm{~km}$ foram retificados.

Em 1995, o Estado de São Paulo, rebaixou a calha do Rio Tietê, em média, 2,5 m e ampliou sua largura de 41 para 46 m, segundo DAEE (2008), obras com um custo de mais de dois bilhões de reais e finalizadas no segundo semestre de 2005.

\subsubsection{Reservação dos volumes à montante}

Na década de 1990, um novo conceito é aplicado: a vazão de restrição com reservação das águas nas cabeceiras das bacias. Desenvolvido pelo coordenador da Comissão Permanente de Enchentes da PMSP, Tecnólogo Carlos de Jesus Campos, segundo PMSP (1991), tais reservatórios foram denominados, na ocasião, de "patamares de inundação". Posteriormente, esta concepção foi desenvolvida na gestão da Prefeita Luiza Erundina, 1989/1993, sendo o "piscinão" sob a Praça Charles Müller, no Pacaembu, inaugurado na gestão seguinte, em 1995.

A partir dessas iniciativas, o DAEE passou a desenvolver o Plano Diretor de Macrodrenagem do Alto Tietê - PDMAT, implantando reservatórios nas sub-bacias da BAT, como na do Tamanduateí, onde propôs 34 reservatórios, dos quais foram construídos, até 2008, 18, num total de reservação de $3.848 .664 \mathrm{~m}^{3}$.

\section{Inundações}

Na BAT as inundações mais significativas do final do século XIX e ao longo do século XX foram em 1893 (retratada por Benedito Calixto), 1906, 1918, 1926, 1929, 1947, 1958, 1963, 1966, 1976, 1983, 1991, 1994, 1996 e 1999. No século XXI, em praticamente todos os anos ocorreram inundações nos principais rios da BAT, em especial, em 2000, 2005, 2009 e 2011, amplamente divulgados pela imprensa.

Cabral e Jesus (1994) constataram que, em virtude da urbanização, a partir de 1960, houve um agravamento substancial das inundações na BAT, com um aumento no número de pontos de inundações, passando de 125 no verão de 1978/79, para 420 em 1991, destacando o dia 19 de março de 1991, com um acumulado de chuvas de $121 \mathrm{~mm}$, que provocou inundações no Tietê, Pinheiros e Tamanduateí, resultando em 20 mortes e cerca de 12.000 chamadas ao corpo de bombeiros. Rocha (1992) aponta também este crescimento significativo: 147 em 1980; 185 em $1981 ; 420$ em 1983. Stevaux et al. (2010) identificaram 500 pontos críticos de inundação nos anos de 1990.

No dia 24 de maio de 2005, no auge do outono, a BAT foi assolada por 140,4 mm de chuvas, registradas na estação do Mirante de Santana. O rebaixamento do Rio Tietê estava em sua fase final, com sua capacidade máxima prevista em projeto, entretanto, as águas do Rio Tietê ocuparam novamente seus espaços. 
Pereira Filho et al. (2004), analisaram as chuvas e as ocorrências de inundações entre 2000 e 2004 e concluíram que a maioria das inundações na BAT, cerca de 67\%, estão associadas ao fenômeno de "ilha de calor", induzido pela circulação de brisa marítima, sendo que o núcleo de alta freqüência de chuvas intensas na região é até três vezes maior que nas áreas vizinhas.

No verão de 2009/2010, toda Região Sudeste do Brasil sofreu novamente com intensas chuvas, com um acumulado de $550 \mathrm{~mm}$ nos meses de dez, jan. e fev. no Mirante de Santana, segundo Ciloni e Biondo (2010). Na ocasião a Vila Romana, situada na zona Leste de São Paulo, ficou meses inundada. O INPE já havia alertado as autoridades, estadual e da Capital paulista, desde meados de 2009, da ocorrência, neste período, de chuvas acima da média na região, decorrente do fenômeno El Niño.

Segundo apurou Uchinaka (2009), a ocorrência das inundações na Vila Romana, na ocasião, foi decorrente da gestão do sistema de macrodrenagem:

\begin{abstract}
As seis comportas da barragem da Penha [...] foram completamente fechadas às 2 h50 do dia 8 de dezembro [...]. Somente dois dias depois, às $17 \mathrm{~h} 20,[\ldots]$ foram abertas. Os dados, fornecidos pelo engenheiro responsável pela barragem, João Sérgio, indicam que houve uma clara escolha da empresa responsável: alagar os bairros pobres da zona leste para evitar o alagamento das marginais [...]. Sérgio explicou que a decisão vem da direção da Emae (Empresa Metropolitana de Águas e Energia). [...]. O engenheiro argumenta que cada barragem [são quatro] é responsável apenas por administrar o fluxo de água do local e não sabe o que acontece nos outros pontos, porque não há comunicação. Mas ele acredita que as comportas foram abertas nas barragens de cima, em Mogi, e isso influenciou no alagamento da região da zona leste. [...] Moradores e deputados estaduais fizeram nesta quarta-feira (17) uma inspeção no local [e acusam] o governo do Estado e a prefeitura de manterem a água represada além do necessário como forma de obrigar as famílias a deixarem a região, onde será construído o Parque Linear da Várzea do Rio Tietê (UCHINAKA, 2009).
\end{abstract}

A partir de 2005 e, principalmente, em 2009/2010, autoridades e técnicos dos governos estadual e municipal (Capital) apontaram como condicionantes das inundações o excesso de chuvas, a não conclusão das obras do PDMAT, a falta ou insuficiência do desassoreamento do Tietê, além do excesso de lixo nas ruas, este último com um peso muito maior, responsabilizando, portanto, o cidadão comum, estabelecendo uma tese oposta ao que apontou Santos (2002).

A tendência do aumento da freqüência e intensidade das inundações coaduna com estudos de Pereira Filho; Santos e Xavier (2007) onde, entre 1936 e 2005, houve um aumento médio de $400 \mathrm{~mm}$ de chuvas por ano na RMSP, com uma mudança importante no regime de chuvas, que passaram a ser mais intensas e em forma de tempestades, indicando que as estruturas hidráulicas, implantadas e em projeto, não são capazes de suportar as vazões cada vez elevadas no Rio Tietê que, segundo DAEE (2002), em 1894 era de $174 \mathrm{~m}^{3} / \mathrm{s}$, passando, com as últimas intervenções, para $1.060 \mathrm{~m}^{3} / \mathrm{s}$ na altura do "Cebolão". Além disso, a ampliação dos espaços construídos na RMSP vem alterando significativamente o comportamento fluvial do Rio Tietê, tanto indiretamente, pela expansão urbana, avançando nas sub-bacias contribuintes, quanto diretamente, por meio de obras destinadas a alterar o leito menor, transformado em calha, incorporando o leito maior e as várzeas à cidade.

\title{
6. Bacia do Rio Baquirivu Guaçu
}

A Bacia do Rio Baquirivu Guaçu, afluente da margem direita do Rio Tietê, ocupa uma área de 165,5 km². Para efeito de comparação a Bacia do Rio Aricanduva possui $100 \mathrm{~km}^{2}$, a do Pirajussara, $72 \mathrm{~km}^{2}$, sendo inferior somente a do Rio Tamanduateí, 320 km². Em Guarulhos 
corresponde a 145,6 km² e em Arujá 19,9 km², onde estão suas nascentes. Possui uma declividade geral de 2,24 m/km, com 25 km de extensão.

A bacia apresenta forte assimetria de suas características geoambientais. Sua vertente norte, margem direita, é composta por rochas cristalinas, solos rasos, terrenos com altitude acima

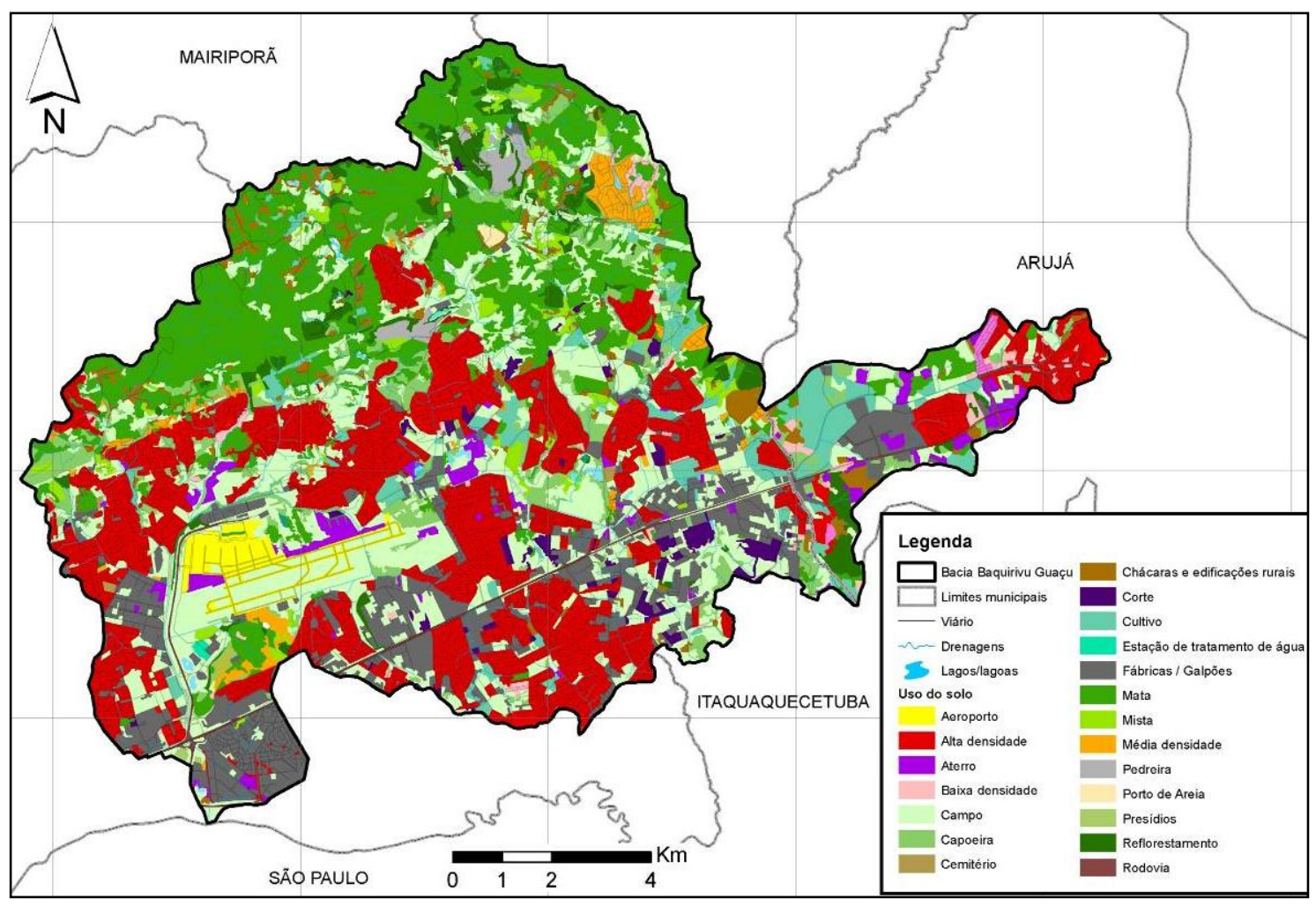

de 1000 m (montanhas e morros) e altas declividades. Na margem esquerda, ao sul, ocorrem predominantemente rochas sedimentares, baixas declividades (morrotes e planícies). As condições geomorfológicas da vertente norte geraram uma rica rede de drenagem, caracterizada por um padrão de drenagem dendrítico, com canais encaixados, com uma tendência à concentração, com altas energias de escoamento até a bacia sedimentar, onde passa a ter um padrão de drenagem subparalelo, com vales mais amplos e menor energia de escoamento, que caracteriza a vertente sul, conforme a Figura 06.

Segundo Campos (op cit.) a área da margem direita da bacia possui 105,6 km² e a esquerda com 59,8 $\mathrm{km}^{2}$. Calculou ainda a densidade de drenagem, que na margem direita corresponde a $2,32 \mathrm{~km} / \mathrm{km}^{2}$ e a esquerda $0,92 \mathrm{~km} / \mathrm{km}^{2}$ e identificou que alguns afluentes da margem direita do rio Baquirivu Guaçu possuem declividades médias acima de 10\%, enquanto na margem esquerda não passam de $4 \%$.

Figura 06. Rede de drenagem da Bacia do Rio Baquirivu Guaçu e do Rio Tietê (CAMPOS, 2011).

Tais condicionantes geofisiográficos favoreceram a ocupação inicial da vertente sul que se encontra hoje quase totalmente urbanizada. Na vertente norte, menos favorável à ocupação urbana, encontram-se ainda os últimos fragmentos da Mata Atlântica, que representam cerca de $51,8 \%$ da área da bacia, conforme a Figura 07. 

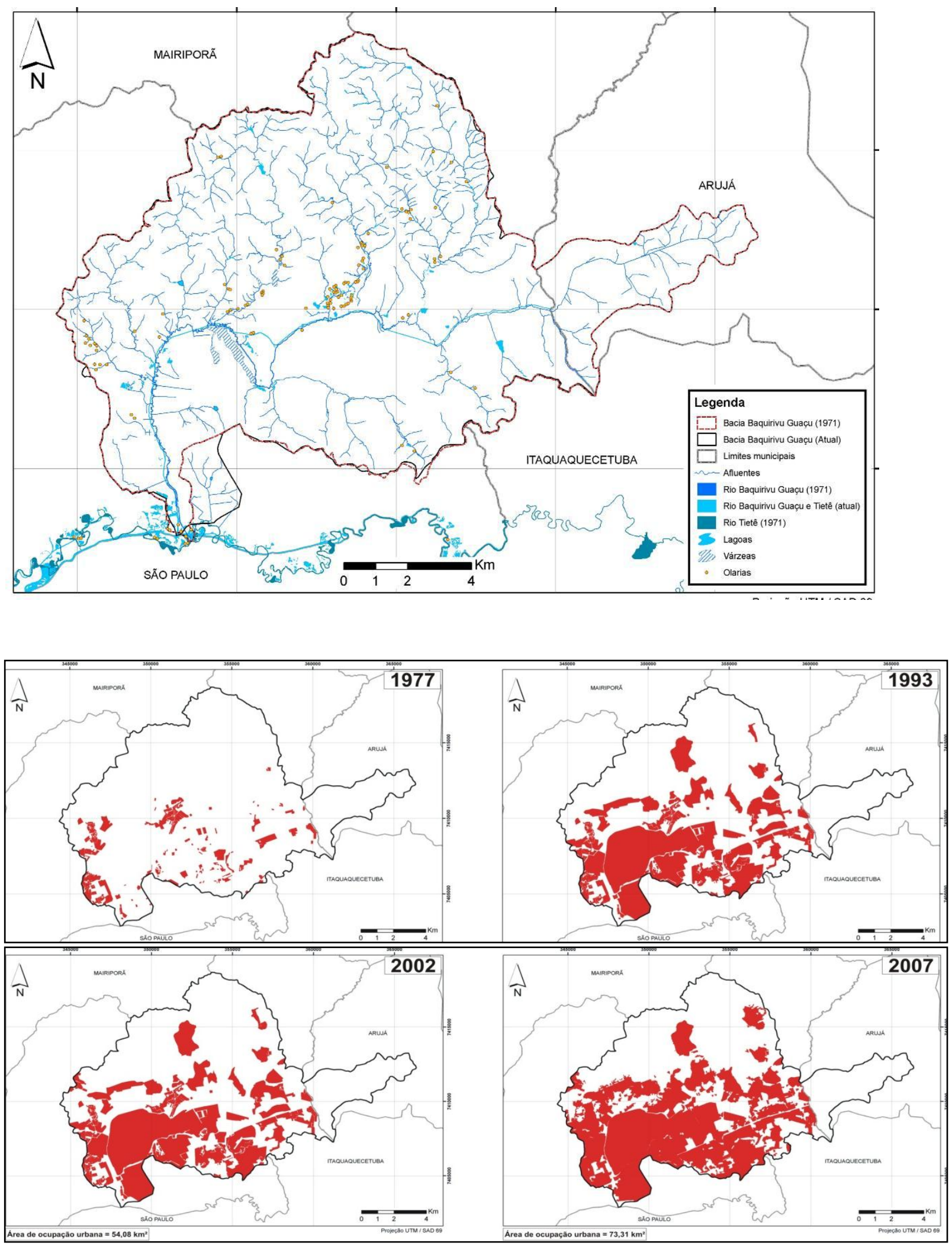

Evolução da área urbana na Bacia do Rio Baquirivu Guaçu, segundo (CAMPOS, 2011). 
No trecho médio de seu curso, destaca-se o Aeroporto Internacional de São Paulo/Guarulhos, com área de $14 \mathrm{~km}^{2}$, implantado entre 1979 e 1985, alterando seu regime fluvial, com a retificação do canal, reduzindo em cerca de $2 \mathrm{~km}$, o aterramento de 13,3 $\mathrm{km}^{2}$ de várzeas e a impermeabilização do solo (CAMPOS, op cit.).

Além desses impactos, o aeroporto provocou, antes, durante e depois de sua construção, um processo de adensamento em seu entorno, onde as áreas de menor valor de mercado, justamente por serem mais degradadas ambientalmente, como as várzeas do Rio Baquirivu Guaçu, apresentando também condições sanitárias insatisfatórias, atraíram, por essa razão, famílias carentes. Além disso, o potencial de emprego e renda prometido pelo empreendimento e amplamente noticiados pelos periódicos locais e regionais, propiciou a ampliação de núcleos urbanos próximo ao aeroporto de maneira precária. A Figura 08 demonstra a evolução de sua área urbana.

\subsection{Inundações}

À medida que a Bacia do Rio Baquirivu Guaçu se urbanizava, a percepção das comunidades era de que aumentava a freqüência e intensidade das inundações registradas por periódicos da época. Entretanto, não é possível estabelecer uma relação direta entre as obras realizadas nos cursos d'água e o regime das inundações. Isso porque, a inundação é um fenômeno natural que passa a se tornar problema à medida que estruturas urbanas ocupam os espaços naturais das águas. Ademais, não há registros da frequência e intensidade das inundações antes dos anos 1970 na Bacia do Rio Baquirivu Guaçu. Entretanto, seus aspectos naturais indicam uma área naturalmente propícia à ocorrência de inundações naturais intensas e freqüentes.
Após a eliminação dos pequenos meandros do Rio Baquirivu Guaçu, entre os anos de 1975 e 1976, pelo DAEE com apoio da Prefeitura de Guarulhos, aumentaram os registros de ocorrências de inundações atingindo áreas urbanizadas, conforme o Jornal O Repórter de Guarulhos de 02 de fevereiro de 1977: "no dia $1^{\circ}$ de fevereiro [1977], [...] perto de cem pessoas ficaram desabrigadas e as aproximadamente 60 famílias [...] sofreram enormes prejuízos com a água que invadiu suas casas, numa repentina inundação do Baquirivu provocada pela [sua] retificação."

No Córrego Cocho Velho, afluente da margem esquerda do Baquirivu Guaçu, segundo relatos de Eduardo França dos Santos, da Defesa Civil (relato verbal em 19 nov. 2010), a frequência de inundações, que interditam a Rodovia Pres. Dutra, é de 2 anos e, ainda, de acordo com o eng. Francisco Acosta Filho da Prefeitura de Guarulhos (relato verbal em 19 nov. 2010), nos dias 07 e 14 de fev. de 1999, as inundações interditaram o aeroporto, pois as águas do Córrego Cocho Velho, que atravessam também o sítio aeroportuário, invadiram suas pistas de pouso e decolagem.

\section{Conclusões}

Considerando o modelo de ocupação que vem sendo seguido na BAT e sua reprodução na Bacia do Rio Baquirivu Guaçu, é possível expor as conclusões a seguir.

\subsection{Diagnóstico}

A ocupação da Bacia do Rio Baquirivu Guaçu pode ser considerada em dois espaços indissociáveis: o da sua extensa várzea e o das vertentes. A ocupação da várzea vem sofrendo danos devido às inundações que atingem o equipamentos públicos como o sistema viário estrutural e o aeroporto, além de comunidades. A ocupação da bacia, devido sua já elevada densidade na vertente 
esquerda, ao sul, além de incrementar as inundações da várzea, vem sofrendo enchentes locais como a do Córrego Cocho Velho, na altura da Rodovia Presidente Dutra.

\subsection{Prognóstico}

A perspectiva de expansão urbana na vertente direita, ao norte do rio, onde ainda subsistem vastas áreas com cobertura vegetal, em sub-bacias que têm maior potencial de geração de escoamentos intensos, que as do sul, indicam uma forte tendência ao aumento das intensidades e freqüências das inundações.

\subsection{Medidas}

Frente a este quadro as medidas governamentais se limitam a obras corretivas compreendendo reservatórios de amortecimento de cheias e de retificação do canal, confirmando o modelo de tratamento das inundações da BAT.

Embora o Plano Diretor de Drenagem de Guarulhos, elaborado em 2008, estabeleça diretrizes para a conservação de áreas vegetadas, várzeas e o controle da expansão urbana ao norte, não há ainda nenhuma legislação com base em mapeamentos específicos, nem medidas efetivas ou propostas de disciplinamento do uso do solo que garantam tais diretrizes.

\subsection{Serviços ambientais ou}

\section{ecossistêmicos}

Persiste a mesma lacuna do modelo de ocupação da BAT de falta de valorização dos serviços ambientais ou ecossistêmicos, das coberturas vegetais e florestas urbanas, como medida não só de atenuação das inundações, mas também da regulação dos escoamentos hídricos das vertentes, reduzindo as áreas de risco, da regulação térmica, com atenuação da ilha de calor urbano e, ainda, dos benefícios paisagísticos - culturais. A valorização destes serviços socializa o aproveitamento dos recursos naturais gerando bem estar a todos os moradores.

\subsection{Modelo}

Entretanto, permanece como determinante o modelo da BAT que reflete o modo de apropriação dos espaços, ou seja, a intervenção antrópica que altera o comportamento fluvial, com geração de inundações, dirigida por interesses econômicos, influenciando nas decisões políticas, favorecendo a especulação imobiliária. Uma das conseqüências deste modelo de ocupação urbana, realizada por comunidades de baixa renda para áreas ainda não valorizados, sujeitos à processos geodinâmicos adversos em áreas de risco, como as sujeitas às inundações e as das vertentes declivosas, aos escorregamentos.

Os poderes econômicos e políticos não se apropriam somente da terra, como mercadoria a ser negociada, mas também dos fenômenos das inundações, como um recurso natural também a ser manipulado, para favorecer a expulsão dos moradores quando lhes convém e, posteriormente, a sobrevalorização das terras, além da execução de obras cada vez mais onerosas ao poder público. Assim a degradação do meio e as próprias obras, constituem poderosos instrumentos para viabilizar 0 aumento do poder econômico de setores imobiliários, impedindo que a lógica vigente da reprodução urbana, manifestada pela sequência: degradação ambiental - tornando um fenômeno natural (inundações) um problema, para a aplicação de obras corretivas - e a valorização dos terrenos, seja rompida. Além disso, o controle urbano numa cidade como Guarulhos inserida numa das maiores conurbações do mundo não é tarefa fácil. A questão, pura e simples, de deficiência na fiscalização para impedir a ocupação nas várzeas e áreas vegetadas é inviável e não resolve o problema fundiário urbano. 


\subsection{Agravamento}

O aumento da frequência e intensidade das chuvas, constatadas em diversos trabalhos científicos, e as condições geomorfológicas da Bacia do Rio Baquirivu Guaçu, indicam um potencial de agravamento das inundações, atingindo importantes equipamentos urbanos, como o aeroporto e a Rodovia Presidente Dutra, além das perdas materiais e de vidas humanas das comunidades que ali vivem.

\section{REFERÊNCIAS BIBLIOGRÁFICAS}

AB'SÁBER, A. N. Geomorfologia do Sítio Urbano de São Paulo, (1957). Tese de doutorado. São Paulo: Instituto de Geomorfologia, Universidade de São Paulo.

BONDUKI, N. Origens da Habitação Social no Brasil: Arquitetura Moderna, Lei do Inquilinato e Difusão da Casa Própria. São Paulo: Estação Liberdade, 1998.

BRITO, F. R. S. de. Defesa contra inundações - Melhoramentos do Rio Tietê. Vol. XIX. Rio de Janeiro: Ministério da Educação e Saúde: Imprensa Nacional, 1926.

CABRAL, E.; JESUS, E. F. R. de. Eventos Fluviais sobre a Grande São Paulo ocorridos em 1991: seus reflexos na vida urbana. Revista da Universidade Estadual de Feira de Santana, n.12, p. 31-54, 1994.

CAMPOS, D. C. de. Inundações: problemas ou fenômenos naturais? A ocupação das várzeas dos principais rios no Alto Tietê e a reprodução deste modelo urbano na Bacia do Rio Baquirivu Guaçu, Guarulhos, SP 2011. Dissertação (Mestrado) - CEPPE - Centro de Pós-graduação e Pesquisa, Universidade Guarulhos, Guarulhos, 2011.

CBHAT - COMITÊ DA BACIA HIDROGRÁFICA DO ALTO TIETÊ. Diagnóstico dos Recursos Hídricos - Relatório Zero. São Paulo: CBHAT, 2000.

Plano da Bacia do Alto Tietê - Sumário executivo. São Paulo: CBHAT/FUSP, 2002.

CILONI, M. C. G.; BIONDO, L. M. Persistência de Precipitação no Verão 2009/2010 ("45 dias de chuvas"). IAG/USP, 2010.

DAEE - Departamento de Águas e Energia Elétrica. Plano Diretor de Macrodrenagem da Bacia Hidrográfica do Alto Tietê: Bacia do Baquirivu Guaçu - Diagnóstico geral e ações recomendadas. Relatório: PDATI-HI-RT-814. São Paulo: Secretaria Estadual de Saneamento e Energia, 2002.

Controle de Enchentes: 10 anos do Plano Diretor de Macrodrenagem da Bacia Hidrográfica do Alto Tietê. São Paulo: Governo do Estado de São
Paulo - Secretaria de Saneamento e Energia, 2008.

EMPLASA - Empresa Paulista de Planejamento Metropolitano. Mapa do Uso e Ocupação do Solo da RMSP. São Paulo: Secretaria de Negócios Metropolitanos, 2002.

FESPSP - Fundação Escola de Sociologia e Política de São Paulo. Distribuição da Renda Média do Chefe de Família por Setor Censitário. In: Avaliação Ambiental Estratégica do Programa Rodoanel, São Paulo: DERSA, 2004. 1 mapa, col. Escala $1: 300.000$.

GUARULHOS - Prefeitura Municipal de Guarulhos. Plano Diretor de Drenagem de Guarulhos: Diretrizes orientações e Propostas. Guarulhos: Prefeitura Municipal de Guarulhos, 2008.

JORGE, F. N. de; UEHARA, K. Águas de Superfície. in: OLIVEIRA, A. M. dos S., BRITO, S. N. A. de, (org.). Geologia de Engenharia, São Paulo: ABGE, 1998.

KARMANN, I. Ciclo da Água: Água subterrânea e sua ação geológica. In: TEIXEIRA, W. et al. (org.). Decifrando a Terra. São Paulo: Companhia Editora Nacional, 2000.

LIGHT. The São Paulo Tramway Light and Company Limited. Planta da Cidade de São Paulo e Municípios Circunvizinhos. São Paulo, Arquivo Histórico Municipal, 1943. 1 mapa, col. Escala 1:50000. Disponível em: "http://www.arquiamigos.org.br/info/info20/i -1897.htm"

http://www.arquiamigos.org.br/info/info20/i1897.htm. Acessado em 19 set. 2010.

LORENZ - MARTIN LORENZ \& CIA. LTDA. Mapa Falk São Paulo. São Paulo, Arquivo Histórico Municipal, 1952. 1 mapa, col. Escala 1:25000 - 1:40000. Disponível em: "http://www.arquiamigos.org.br/info/info20/i -1897.htm" Acessado em 19 set. 2010.

MATTES, D. O Espaço das Águas: As Várzeas de Inundação da cidade de São Paulo. 2001. Dissertação (Mestrado) - Faculdade de Arquitetura e Urbanismo, Universidade de São Paulo, São Paulo, 2001. 
NADALIN, V. G.; IGLIORI, D. C. Evolução urbana e espraiamento na Região Metropolitana de São Paulo. Rio de Janeiro: Instituto de Pesquisas Econômicas Aplicada, 2010. (Texto para discussão no 1481).

OLIVEIRA, A. M. dos S., et al. Bases Geoambientais para um Sistema de Informações Ambientais do Município de Guarulhos. 2009. Guarulhos: Universidade Guarulhos - Centro de Pós-Graduação, Pesquisa e Extensão, 2009.

PEREIRA FILHO, A. J., et al. Enchentes na Região Metropolitana de São Paulo: aspectos de mesoescala e avaliação de impactos. In: CONGRESSO BRASILEIRO DE METEOROLOGIA, 13., 2004, Fortaleza, Anais... Fortaleza, CE, 2004.

PEREIRA FILHO, A. J.; SANTOS, P. M. dos; XAVIER, T. de M. B. S. (org.). Evolução do Tempo e do Clima na Região Metropolitana de São Paulo. São Paulo: Linear B; IAG/USP, 2007.

PMSP - Prefeitura Municipal de São Paulo. Ofício no CPE/10/91 - Secretaria das Administrações Regionais/SAR - Assessoria Técnica de Obras e Serviços/Atos, 23 de abril de 1991.

REPÓRTER DE GUARULHOS. Cumbica inundada; e não choveu. O Repórter de Guarulhos. Guarulhos, 02 de fev. 1977, ano I, n. 2, p. 4.

RICCOMINI, C.; GIANNINI, P. C. F.; MANCINI, F. Rios e Processos Aluviais. In: TEIXEIRA, W. et al. (org.). Decifrando a Terra. São Paulo: Companhia Editora Nacional, 2000.

SALLES, D.; SALVO, M. P. de. Não há uma política de remoção de ocupações irregulares. Revista Veja, São Paulo, 16 dez. 2009. Disponível em: http://vejasp.abril.com.br/noticias/lixo-foivoce-quem-jogou. Acessado em 26 out. 2010.
SANTOS A. R. dos. Geologia de Engenharia: conceitos, métodos e prática. São Paulo: Instituto de Pesquisas Tecnológicas - IPT: ABGE, 2002.

SEABRA, O. C. de L., Os meandros dos rios nos meandros do poder: Tietê e Pinheiros valorização dos rios e das várzeas na cidade de São Paulo (1987). Tese de doutorado. São Paulo: FFLCH/USP.

SEMPLA - Secretaria Municipal do Planejamento, Orçamento e Gestão da Cidade de São Paulo. Histórico Demográfico do Município de São Paulo. São Paulo: Secretaria de Planejamento, 2010. Disponível em:

http//sempla.prefeitura.sp.gov.br/historico/i mg/mapas. Acessado em 12 set. 2010.

SERRA, G. O espaço natural e a forma urbana. São Paulo: Nobel, 1987.

STEVAUX, J. C. et al. Floods in urban areas of Brazil. In: LATRUBESSE, E. M. (editor) Natural hazards and human exacerbated disasters in Latin América. Elsevier. P 245 266, 2010.

TUCCI, C. E. M. Gestão de águas pluviais urbanas. Brasil: Ministério das Cidades Secretaria Nacional de Saneamento Ambiental. Programa Saneamento para Todos, 4 vol., 2006.

UCHINAKA, F. Manejo de comportas encheu bairros pobres. Uol notícias, São Paulo, 17 de dez. 2009. Disponível em: http://exbancario.blog.br/2009/12/manejode-comportas-encheu-bairros-pobres-de-saopaulo-e-o-governo-e-prefeitura-de-spjogando-a-populacao-pobre-de-s-paulo-noesgotona-merdana-lama/. Acessado em 20 abr. 2010 